\title{
Application of Function Partition Layout Based on Genetic Algorithm in New District Road Design
}

\author{
Weixiang $\mathrm{Xu}^{1, \mathrm{a}}$ and Sen $\mathrm{Qiu}^{2, \mathrm{~b}}$ \\ School of Traffic and Transportation, Beijing Jiaotong University, China \\ awxxu@bjtu.edu.cn, b13120885@bjtu.edu.cn
}

Keywords: Function partition; Genetic algorithm; Road design; Layout

\begin{abstract}
The investment in the country to improve the urban traffic congestion is often not ideal. At the time of the establishment of Xiong'an New District, the problem of traffic congestion is solved from the top design, to build a new environment city which is suitable for human habitation. In this paper, the genetic algorithm will be used to optimize the layout of the functional partition, and then the road network will be planned to get the optimal road design, which solve the fundamental problem of traffic congestion from the source, that grate changes of travel demand. After the case validation, this method is feasible, and provides a good idea for the rode planning of Xiong'an New District now and later.
\end{abstract}

\section{Background}

National President Xi Jinping pointed out that the key task of planning and constructing Xiong'an New District is constructing a green sapiential Metro and building an international smart city. Smart city must be based on intelligent transportation and intelligent traffic must planned ahead of time, as a result the function partition-oriented road design is bound to study necessarily. However the land utilization of new urban district has not yet been developed to obtain the survey data, it is necessary to seek the theoretical method suitable for urban road network system planning.

The main goal of the new district establishing is to ease the non-capital functions. As a result, how to optimize the building layout with different functions including "Some factories", "Some schools", "Some hospitals", " Some institutions "and so on is a matter to be considered.

The first problem with the new district layout is the lack of overall planning. According to statistics, by the end of 1997 China's urban development zones (including high-tech zones) have reached 4210 , planning area of $12357 \mathrm{~km}^{2}$, while the actual development were only $1852 \mathrm{~km}^{2}$, accounting for $15 \%$. By the end of 1995, 52 national high-tech zones nationwide developed a total land area of $132.94 \mathrm{~km}$, accounting for only $7 \%$ of the total development zone. The importance of the overall planning and function layout of the new district is evident $[1,2]$.

\section{Introduction}

Urban function partition is that partitioning all kinds of material elements such as factories, warehouses, residence according to the function requirements, to form an interconnected and well-organized organic whole, creating a favorable environment and conditions for the city's activities. It is an important method for overall urban planning to determine the land using and spatial layout form according to the principle of function partition.

At the end of the 19th century, the "garden city" theory distinguishes the road with different nature which achieves the function division of the road. There was a "neighborhood unit" planning in the United States, emphasizing the safety of pedestrian traffic [3].

In the first half of the 20th century, Corbusier proposed in the "radiant city" planning program that separating the contradictions between motor vehicles and pedestrians traffic completely through fly-over crossing in the city [4].

Over the past 30 years, a large number of scholars have studied the problem of traffic network design with bi-level programming method. Friesz, Magnanti, Wong, Boyce, Yang and others have reviewed the research results of bi-level programming model and algorithm respectively in NDP 


\section{[5].}

In the existing planning of new district, how many lateral, lengthwise, radiant, circular road network planning is determined first to build plot and other facilities in each respective road division. Such planning makes the traffic in the future function area difficult to predict. And the situation of a road crowded and other road with no one to go is usual. Or bi-level programming model [6], expert experience, four-step model [7], total quantity control method [8], node importance method [9] and traffic location method [10] is used to plan road network in the original building partitions.

\section{Algorithm}

Genetic algorithm (GA) is an algorithm simulating the biological evolution mechanism of nature, which is, following the rule of survival of the fittest, which is, useful reservations and useless removal in the process of optimization.

Its characteristic is encoding the parameters, without any prior knowledge about the system. It has a parallel search along a variety of routes, and will not fall into the trap of local optimal solution, and then find the overall optimal point in much local optimal solution, is a global optimization method. Genetic algorithm flow is shown in Figure 1.

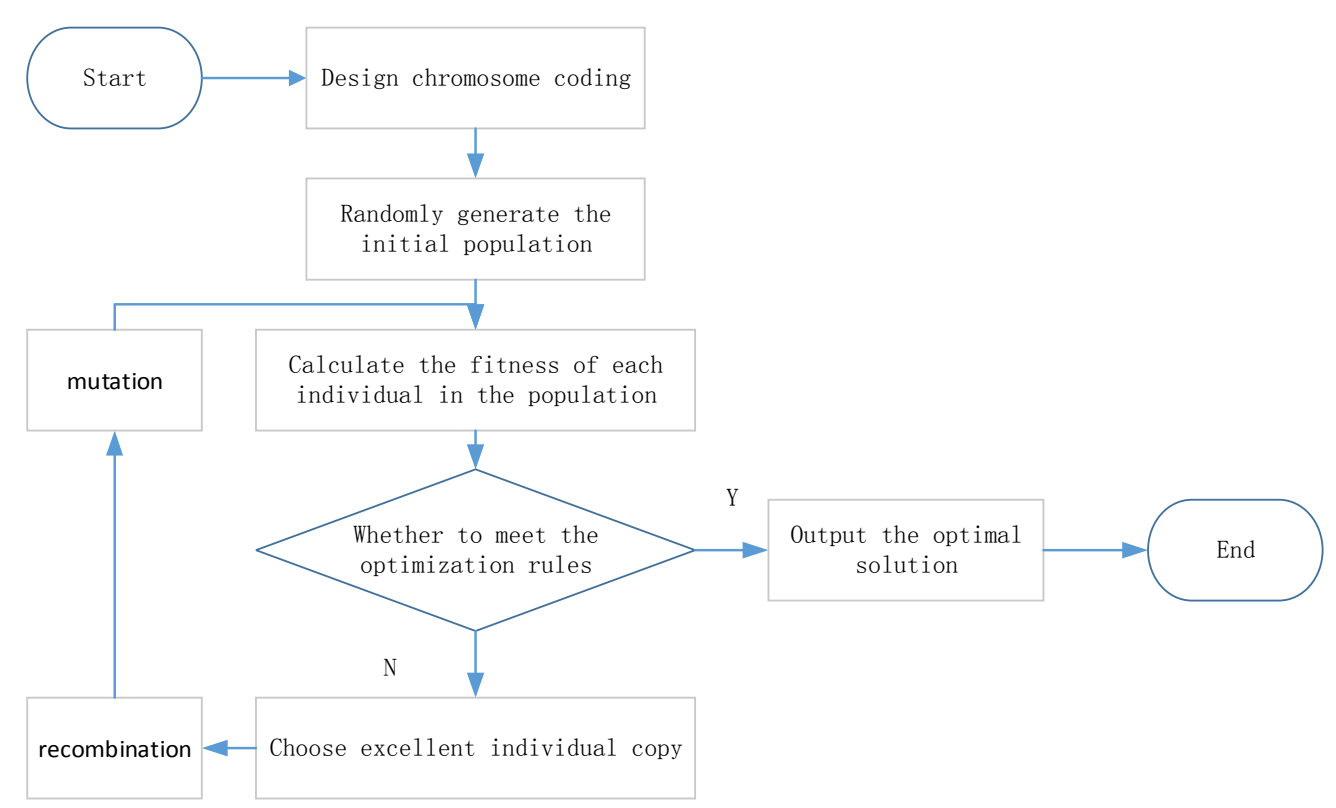

Fig. 1. The flow chart of genetic algorithm

\section{Model}

Simplified model shown in Figure 2. All the irregular building partitions are calculated based on the largest diameter as an enclosing rectangle, and the objective function can be expressed as

$$
C_{\text {min }}=\sum_{i=1}^{n} \sum_{j=1}^{n} P_{i j} Q_{i j} D_{i j}
$$

The distance between building partitions is as follows:

$$
z_{i k}=\left\{\begin{array}{l}
1, \text { the building } i \text { is in the } k \text { line } \\
0, \text { others }
\end{array}\right.
$$




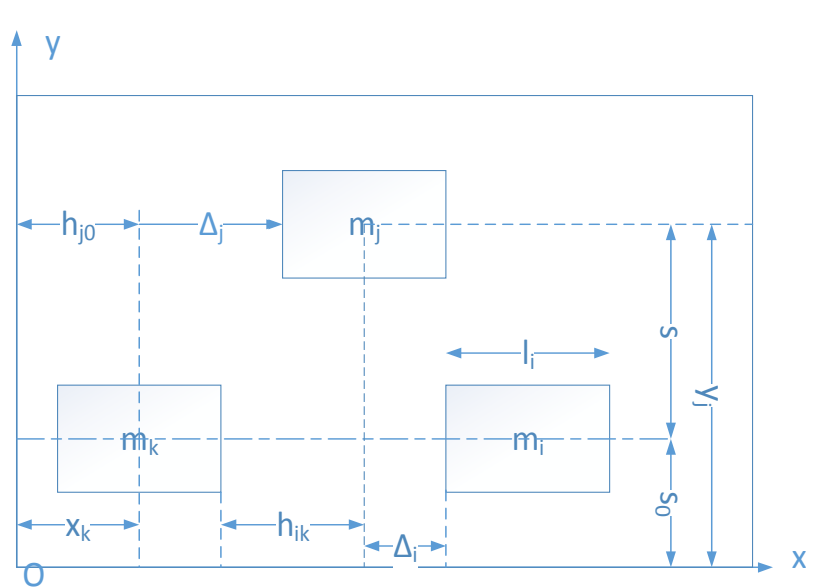

Fig. 2. Building partition model

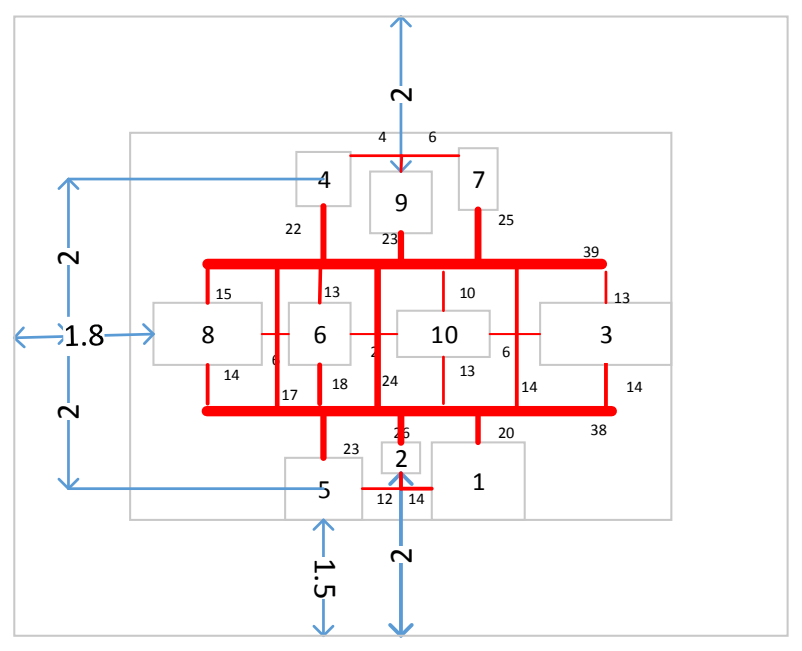

Fig. 3. The results of the road network planning

The solution formula of the abscissa of building partitions:

$$
x_{i}=x_{k}+\left(l_{i}+l_{k}\right) / 2+h_{i k}+\Delta_{i}=h_{k 0}+\Delta_{k}+\left(l_{i}+2 l_{k}\right) / 2+h_{i k}+\Delta_{i}
$$

The solution formula of the ordinate of building partitions:

$$
\left\{\begin{array}{l}
y_{i}=(k-1) s+s_{0} \\
\sum_{k=1}^{m} z_{i k}=1
\end{array}\right.
$$

If $z=1, i=1,2,3, \ldots, \mathrm{n} ; k=1,2,3, \ldots \mathrm{m}$. The abscissa and the ordinate satisfy the constraint condition that the same row of building partitions don't overlap,

$$
\left|x_{i}-x_{j}\right| \geq\left[\left(l_{i}+l_{k}\right) / 2+h_{i j}\right] z_{i k} z_{j k}
$$

$C$ is the total cost of the moving; $n$ is the number of building partitions; $m$ is the total number of building partitions rows; $l_{i}$ is the length of the building partition $i ; h_{i j}$ is the minimum spacing demanded between the building partition $i$ and the building partition $j ; h_{i 0}$ is the horizontal minimum spacing demanded between the building partition $i$ and the land boundary; $\Delta_{i}$ is the clear spacing between the building partition $i$ and the building partition $i-1$, and it is at the range of $[0,1.5]$ in order to facilitate the calculation; $S$ is the line spacing of the building partition; $S_{0}$ is the distance from the first line of building partition to the land boundary; $X_{i}$ is the $\mathrm{x}$ coordinate of the center of the building partition $i$; $Y_{i}$ is the $y$ coordinate of the center of the building partition $i$; $P_{i j}$ is the transportation cost of per person and per unit distance between the building partition $i$ and the building partition $j ; Q_{i j}$ is the traffic frequency between the building partition $i$ and the building partition $j ; D_{i j}$ is the rectangular distance between the building partition $i$ and $j$.

\section{Case}

Assuming that 10 different building partitions with different functions will be built in a land of $10 \mathrm{~km} \times 8 \mathrm{~km}$. Dimensions are shown in Table 1 .

Encoding: Encoding expression adopts extended transposition of two lists that the building partition symbol and clear spacing: $\left[\left\{m_{1}, m_{2}, \ldots m_{n}\right\},\left\{\Delta_{1}, \Delta_{2}, \ldots \Delta_{n}\right\}\right]$.

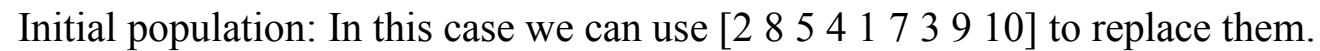

Penalty term: Because of the use of word wrap strategy, the building partition will be not beyond 
the land area in the $x$ direction. Therefore, we just need judge whether building partition in the last Table 1 The building partition size (unit: $\mathrm{km}$ )

\begin{tabular}{c|l|l|l|l|l|l|l|l|l|l}
\hline building partition & 1 & 2 & 3 & 4 & 5 & 6 & 7 & 8 & 9 & 10 \\
\hline size & $1.2 \mathrm{x}$ & $0.5 \mathrm{x}$ & $1.7 \mathrm{x}$ & $0.7 \mathrm{x}$ & $1.0 \mathrm{x}$ & $0.8 \mathrm{x}$ & $0.5 \mathrm{x}$ & $1.4 \mathrm{x}$ & $0.8 \mathrm{x}$ & $1.2 \mathrm{x}$ \\
& 1.0 & 0.4 & 0.8 & 0.7 & 0.8 & 0.8 & 0.8 & 0.8 & 0.8 & 0.6 \\
\hline
\end{tabular}

row in the $y$ direction is beyond the area. This article takes the maximum penalty number $T$ is positive 500 .

Fitness function: The fitness function of the chromosome $v_{k}$ is defined as $C_{k}+P_{k}$ countdown.

Selection: use rotary method selection mechanism, that is, the probability that each individual was selected is proportional to its fitness.

Crossover: The PMX method is used to deal with the permutation crossover operation of the building partition, and the academic crossover method is used to deal with clear spacing sequence.

Mutation: Mutation operation is used in the clear spacing of the building partition only. Assuming that the clear spacing of the given chromosome sequence is $\left\{\Delta_{1}, \Delta_{2}, \ldots, \Delta_{i}, \ldots \Delta_{\mathrm{n}}\right\}$, and appoint its mutation point in the light of the mutation probability. $r$ is a given integer. [ $\left.U_{\min }, U_{\max }\right]$ is the range of the clear spacing of the building partition, then $r$ clear spacing is generated randomly in this interval $: \Delta_{i}{ }^{1}, \Delta_{i}{ }^{2}, \ldots, \Delta_{i}^{r}$, which is used to replace the mutation point to produce $r$ new individual chromosomes, from where the best one is picked to replace the original chromosome.

$R=10,\left[U_{\min }, U_{\max }\right]=[0,1.5]$

Operating parameters: The population number is 50 , and the termination algebra is 200 . The crossover probability is 0.6 , and the mutation probability is 0.1 .

Due to the randomness of the algorithm, the results may not be the same each time to run. But the solution is optimized. You can get some optimized solution if you run a few more procedures, such as the following set of solutions: $\left[\left\{m_{1}, m_{2}, \ldots m_{n}\right\},\left\{\Delta_{1}, \Delta_{2}, \ldots \Delta_{n}\right\}\right]=[5,2,1,8,6,10,3,4,9,7,0.0760$, $1.0802,0.0381,0.0145,0.01532,0.0648,0.0869,0.0048,0.1214,0.1279]$

The corresponding objective function value is 1957. Follow the word wrap strategy, the arrangement of the result above is shown in figure 3 .

In the figure, the numbers next to the red line represent the width of the road, and in a practical application, the four level road that fast-speed road, main road, minor road and bypass is determined in the light of this index where 35 or more is the main road, 15 to 35 is the minor road and below 15 is the bypass.

The follow is a part of the data code:

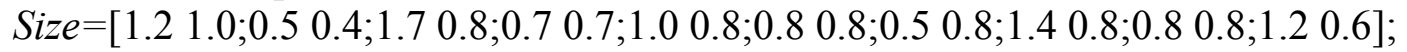

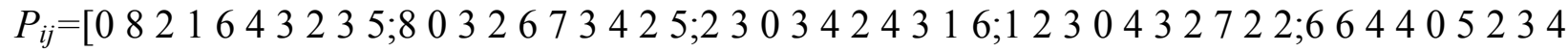
$1 ; 4723505632 ; 3342250444 ; 2437364032 ; 3212434302 ; 5562124220$ ];

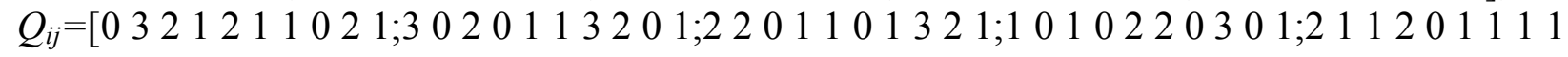
$0 ; 1102102132 ; 1310120233 ; 0233112013 ; 2020133102 ; 1111023320$ ];

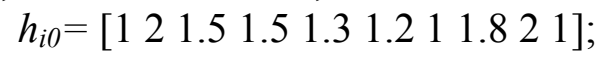

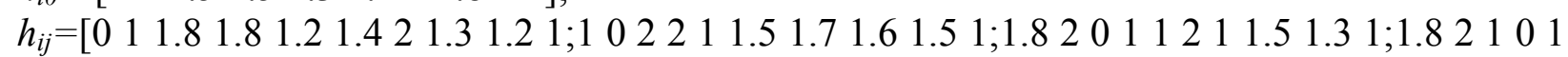

$21.81 .811 ; 1.211101 .711 .721 ; 1.41 .5221 .7022111 ; 21.711 .81201 .211 ; 1.31 .61 .5$

$1.81 .711 .201 .81 ; 1.21 .51 .312111 .801 ; 11111111111110]$;

$s=2 ; s_{0}=1.5$;

$n c h r=50 ; G=200$;

$P c=0.6 ; P m=0.1$;

$T=500 ; H=8 ; r=10$;

$U_{\min }=0 ; U_{\max }=1.5$

\section{Summary}

In the situation of that the new district is everywhere but lack planning, and the old planning model have their own disadvantages. Especially the early planning always refer to the existing historical 
model, such that the traffic condition among each function partition in the new district is not good. The idea of using the genetic algorithm to optimize the function partition provided in this paper provides new thoughts for the planning of the new district. The shortcomings of this paper is that the road network planning can only choose a cross type, do not set the corresponding restrictions such as the cross situation between the level roads, road network density, network spacing and so on. The result will be more desirable if combining with the optimized route selection system.

\section{Acknowledgements}

This work was supported by National Natural Science Foundation of China $(61272029,61672002)$

\section{References}

[1] Y Yang. Study on Small Town Road Network Planning. (M.S., Lanzhou Jiaotong University, China, 2013), p.28. (In Chinese)

[2] J.Y. Tang: City Road and Bridge, Vol 43 (2016) No.3, p.24. (In Chinese)

[3] Q. Liu. Study on Public Facilities Planning in Residential Areas in the Neighborhood Center Mode. (Urban \& Rural Governance and Planning Reform- Proceedings of Annual Conference of China City Planning, China, 2014), p.12. (In Chinese)

[4] X. Ji and B.K. Xiao: Architecture and Culture, Vol. 2 (2017) No.2, p.122. (In Chinese)

[5] Z.Y. Gao, H.Z. Zhang and H.J. Sun Journal of Transportation Systems Engineering and Information. (China Science Press, China, 2004), p.1. (In Chinese)

[6] Y.F. Huang and T. Liu: Journal of Traffic and Transportation Engineering, Vol. 12 (2006) No.4, p. 105. (In Chinese)

[7] Y. Wang. LUTIPSS: GIS-based Land Use and Transportation Integrated Planning Support System. Urban Planning Society of China, (The People's Government of Guiyang Municipality. New normal: Heritage, 2015), p.15. (In Chinese)

[8] P. Yang and Q.F. Yang: Journal of Changsha University, Vol. 4 (2016) No.2, p.84. (In Chinese)

[9] C.X. Ren, F.S. Liu and L. Zhou: Journal of Shandong University of Science and Technology, Vol. 8 (2014) No.1, p.100. (In Chinese)

[10]Z.P. Xi. Research on the Optimization Method of Metropolitan Highway Network Structure and Layout. (PH.D., Southeast University, China, 2016). P.35. (In Chinese) 